\title{
Studio Improv as Compositional Process Through Case Studies of Ghanaian Hiplife and Afrobeats
}

\author{
Leila Adu-Gilmore
}

\section{Introduction}

Drawing on interviews and an analysis of music by two Accra-based producers, Appietus (Appiah Dankwa, b. 1977) and DJ Breezy (Patrick Sika-Nartey, b. 1990), I will show how formal and informal education networks and geographic location shape musical production in Accra. Appietus' richly harmonic music is best approached through the tradition of highlife music, so I will give a brief history of Ghanaian musical styles of the past seven decades, from the pre-independence period to the emergence of electronic music in the 1980s. A series of transcriptions will serve to focus my discussion of Appietus' music. In analyzing DJ Breezy's timbrally precise minimalist music, I focus on his number one single, 'Tonga' (2014), using ecological acoustics, a form of critical analysis that looks at how music is perceived in space. These producers' music demonstrates that, as in many other forms of non-notated music, the definitions of the words 'composition' and 'improvisation' continuously disrupt each other. This blurring of the creative processes of improvisation and composition is highlighted in the studio, where hardware and software serve as both performative and compositional instruments. Although Black music tends to be read through an ethnographic lens focused on rhythm, text and culture, I hope to show that the blending of music analysis and on-site interviews suggests new methodological frameworks on its study.

\section{Pre-Independence to Electronic “Ghana Music”}

Contemporary Ghanaian music producers are creating a combination of styles that have their roots in music from overseas and in Ghanaian highlife, which is itself a musical hybrid. In a recent essay on "Contemporary Ghanaian Popular Music," John Collins states that although "highlife" was the name coined in the 1920s, the form is part of a tradition of transcultural music that began in the $1880 \mathrm{~s}$ in the beginning of the British colonial period. Highlife is an admixture of brass band music, Western classical music, guitar and accordion music from sailors, marching music of southern Ghana, as well as coastal guitar styles and street music by local ballroom dance orchestras. The importance of music in Ghanaian society is demonstrated by the fact that the thriving live entertainment sector managed to continue throughout the 1970 s military regimes and economic collapse. In the 1980s, however, Flight Lieutenant Jerry John Rawlings staged two coups, and his strict policies incapacitated popular music and musicians. Rawlings imposed a nighttime curfew that destroyed musical nightlife and additionally imposed a $160 \%$ import tax on musical instruments. Many musicians were, as a result, attracted to the Gospel music sector, where night performance was not an issue and where the church was exempt from the import tax. Under the old colonial rule, drums and dancing were not allowed in the church services, however, church music soon included these traditional elements and the practice of including traditional instruments grew stronger as highlife and other fusion musicians joined the Gospel sector. Therefore, the value of live music in Ghana can be seen in its ability to both exist throughout times of political struggle and encompass different influences and styles.

The skill of Ghanaian musicians in adapting and creating new musical styles from the realms of traditional Ghanaian music, overseas influences, and contemporary styles was mirrored in the era of electronic music. With its blend of drum machines, synthesizers and highlife, Burger Highlife was the first genre of electronic music of note and it was a precursor of other electronic styles to come. "Burger Highlife" was named after the electronic highlife produced by the many bands immigrating to Hamburg in Germany in the 1980s. Among these emigrants were the successful Lumba brothers, including Sarkodie who is featured on Appietus' "Emere" discussed in the next section of this essay. By the 1990s, Ghanaian artists had begun rapping over electronic hip hop backing tracks from overseas; later, they began to produce the backing tracks themselves. Hiplife began when the rap vocals turned from English to pidgin and to local languages like Twi and Ga. Reggie Rockstone was the first to rap in the hiplife genre, eventually adding highlife and Nigerian afrobeat music to the tracks, and soon producer Panji Ankoff began to include traditional Ghanaian instruments and rhythms with the group, Talking Drums (Shipley 35). In 2011, in order to address the fact that new genres, such as Nigerian and Ghanaian hiplife, highlife, juju and nigerbeats with newer elements of African funky house and hip hop were springing up more frequently, London-based DJ, Abrantee (Abrantee Boateng, b. 1981), created the umbrella term 'afrobeats,' undoubtedly an easier concept for his UK audience to grasp. The defining characteristic of "afrobeats" (like the name of Fela Kuti's "afrobeat" genre, often spelled with an "s") is the audible $3 / 2^{1}$ standard Latin clave pattern in a percussive upper register (as in electronic snare or high hat) with different tempos and dance styles denoting sub-genres, like azonto and more recently, akayidah. I asked DJ Breezy to explain the genre:

Afrobeat now, I think it's like what we are doing now is taking from that of Fela Kuti and, like, the old people but now we've modified it in our own way for us to be able to dance with it . . I think afrobeats in general is about the tempo and the rhythm how it goes, and I think it's taken from the old one, like the old Fela Kuti's afrobeats. If you listen to the samples of the new ones, you will hear some of the 
elements in that one ... That [standard pattern] rhythm makes you dance when you hear that ... so that's the basic one.

Whereas the aptly named 'Hiplife' comes in a direct lineage from hip hop and highlife, 'afrobeats' is somewhat harder to place and lies somewhere in the ever gray area between electronic dance music (EDM) and hip hop.

In terms of electronic sound aesthetics, as the youth in Ghana saw older highlife and Afro-fusion bands as oldfashioned, they were attracted to the highly produced sounds of Burger Highlife, with its mix of synthetic and live musical instruments, due to the association with wealth and modernity. Collins argues that this development is due in part to the disappointment of the current generation with their parents' politics, and a similarly disillusioned response to the passing of the Nkrumah era. This particular taste in electronic sounds would encumber these and future artists' ability to "cross-over" to the international market. Savvy African artists like Yousou N'Dour from Senegal have sometimes created two recordings, one in this synthetic style and one in a world music style to appeal to both audiences (Collins 2012, 229-230). Furthermore, Accra-based music journalist, DJ and label boss, Benjamin Le Brave, believes that the tendency for West audiences to fetishize African musical recordings from the past has affected the reception of newer electronic styles, especially those with distinctive digital processing, such as "auto-tune" used as an effect on vocals. Additionally, other African electronic musicians have successfully collaborated with international artists, such as Angolan Kuduro artists 'Buraka Son Sistema' with Sri Lankan British artist M.I.A., as well as American Kanye West signing Nigerian artists and working with female Nigerian-Canadian producer, Wondergurl (who also cites Timbaland as her biggest influence). Therefore, contemporary Ghanaian producers using the latest production techniques, who have been neglected by international audiences seeking an "authentic" sound, could begin to see a broader appeal in a similar way to these other successful African producers.

\section{Case Studies on Appietus and DJ Breezy}

\section{Forms of Analysis}

In hiplife, afrobeat, hip hop, and other EDM styles, producers are not only recording engineers, they are also the composers of the rhythm, melodies, chords, harmony and depending on the artist, the overall structural shape of the song (i.e. verse/chorus placement and amount of repetitions). Additionally, they may take on other practical and organizational steps to release the final product, in a role similar to that of a film producer (Pras, Guastavino, Cance). Music technology is rapidly progressing; the formats for release (such as mp3s on the internet) and subgenres of hip hop and EDM styles are constantly changing, and part of the role of producers is keeping up with current trends whilst maintaining their own artistic voice.

There is much research on rhythm and text in African popular music styles, African electronic music styles, and American hip hop—these genres, however, remain understudied as standalone composed and improvised art forms. Studies of these genres could incorporate musical transcriptions and harmonic analysis, giving the same scholarly importance to harmony, timbre and arranging as western popular and classical styles. A brief acknowledgment of earlier studies will set into relief the approach adopted in this essay. The historic black practice of using new musical techniques is shown throughout Alexander Weheliye's (2001) work on black cultural production through sound technologies, and Mark Butler shows how producers, including Jeff Mills, improvise and compose music for live shows. John Collins has studied the history, philosophy, symbolism and musical concepts of highlife and transcribes African in alternative notations for the lay music reader. Hip Hop Africa includes two chapters on the subject of Ghanaian hip hop which clearly delineate its history (Collins 2012; Weaver). There is writing on the musical history and social aspects of highlife (Agawu; Collins 2004) and the newer Ghanaian styles of Burger Highlife, gospel and hiplife (Carl; Collins 2012; Jali; Weaver) though these works lack musical analysis and transcription in terms of compositional research. Advocates of transcription of world music as a path to musical understanding include writers on compositional research, composers Béla Bartók and Jack Body and musicologist Kofi Agawu.

The following case studies use different techniques of musical anlaysis, focusing on the respective skills of harmony and timbre in the music of Appietus and DJ Breezy. "Tonga" (2014) was an instant hit on radio stations and with follow-up dance videos online; the track's creator, DJ Breezy, won the VGMA (Vodafone Ghana Music Awards) Producer of the Year in 2015. Controversy over the lyrical theme by rapper/lyricist Joey B, with innuendo on the theme of female anatomy, fueled the song's infamy. By the second bar, the track stands out against other Ghanaian electronic music as shockingly sparse. While the interplay of horizontal and vertical elements is substantive in Appietus' music, DJ Breezy's music appeals in different ways. Therefore, whereas transcription elucidates the construction of Appietus' music, we need to approach DJ Breezy's differently. It is for this reason that I have followed the model of ecological acoustics, a description of sound in aural space, ${ }^{3}$ to account for the harmonically scarce and timbrally rich music production of DJ Breezy. 
Transcription and Analysis: Appietus and "The Revolution"

The multi award-winning, highly respected and prolific producer, musician, and sound-engineer, Appietus, is best known for his artistry in highlife and contemporary afrobeats. Highlife harmony features throughout his 2010 album, The Revolution and in his 2013 compilation, Tip of the Iceberg (2013). "Emere" from Tip of the Iceberg is the track that displays the most highlife features, beginning with the arpeggiated chords reminiscent of highlife guitar. ${ }^{4}$ In a 1999 trip to Ghana, I spoke with leading highlife musician, Mach Tontoh from Osibisa, who said that many highlife elements, such as bass lines and percussion, are linked to Latin American music. Historic aspects of the highlife style and the highlife guitar have been well-documented by Collins in his "Ghanaian Highlife" (Collins 62) and Andrew Kaye's article about guitarist, Koo Nimoo, including its interlocking rhythms, originating from African two finger style guitar playing and Brazilian samba (Collins 76-78). One striking tendency in Highlife is a harmonic progression between two chords that lie a semitone apart (see Figure 1.1). "Emere" appears to be in Lydian mode with an $\mathrm{F}$ tonic. The initial $\mathrm{F}$ major chord steps down by semi-tone to the $\mathrm{E}$ minor chord, returning to $\mathrm{F}$ as the final chord in the sequence. The main vocal line also descends from $\mathrm{C}$ to $\mathrm{F}$. There is a bouncy highlife bassline outlining the semitone-related $\mathrm{F}$ major to $\mathrm{E}$ minor chords (see Figure 1.2). The latter is sometimes substituted for by an Em7 or a G chord.

\section{Click here for audio.}

Appietus 2ga feat. Sarkodie, "Emere." Tip of the Iceberg. Appietus, 2013 by Akwaaba Music.

(Adobe Reader may be required to listen to audio files. The software may require your permission to access this media.)

Figure 1.1. Appietus 2ga feat. Sarkodie, "Emere," Reduction, 0'77"

Tip of the Iceberg: Compilation (2013)
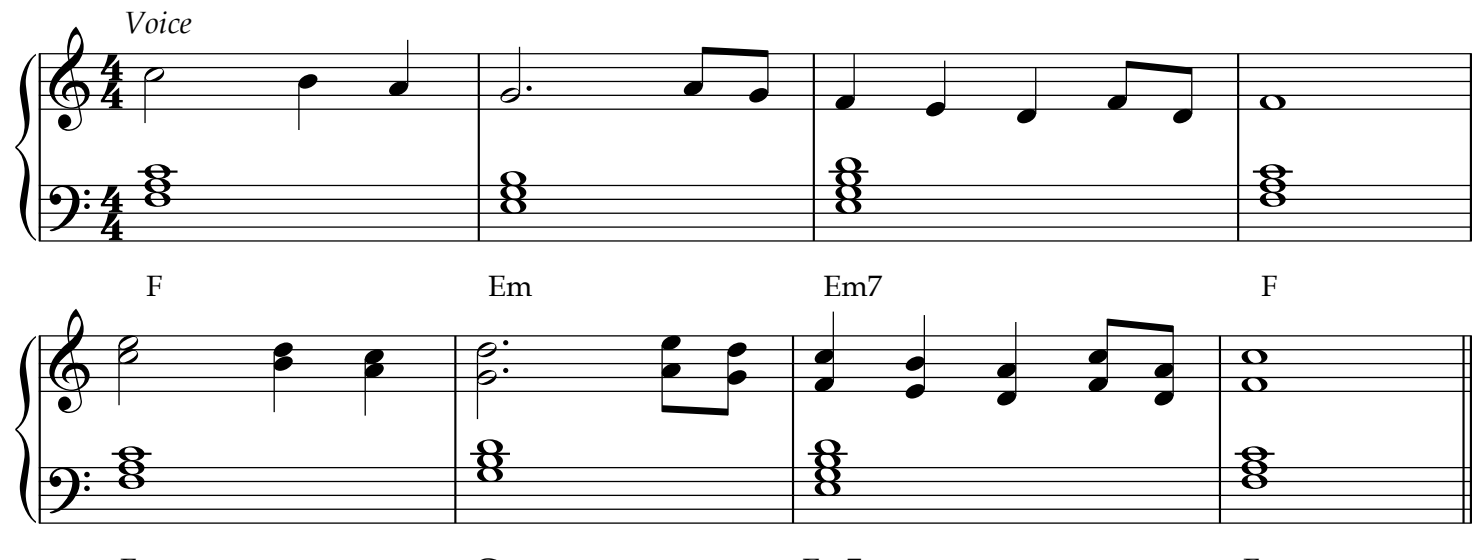

F

G

$\operatorname{Em} 7$

F

Figure 1.2. Vocal and Bass Ornamentation Transcription, 0 '25"
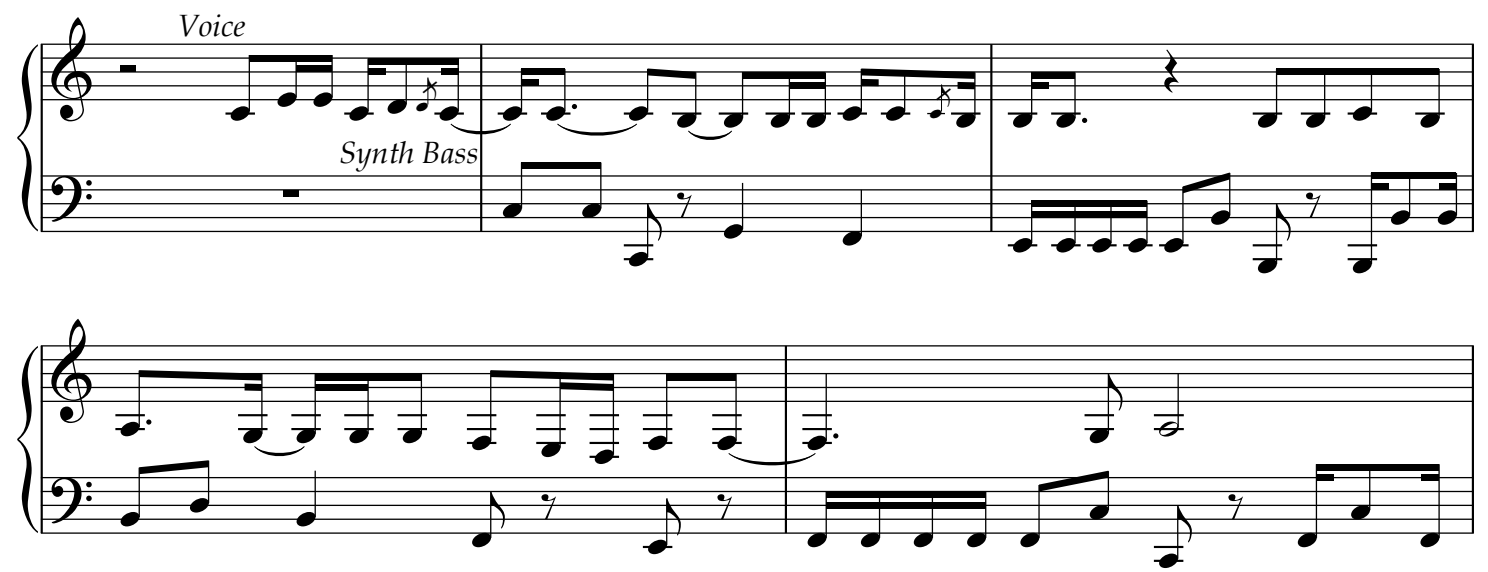

Reduction \& Transcription by Leila Adu-Gilmore 
"Ma Alomoo" (Figure 2) from the album The Revolution (2010) shares a similar semi-tone chord progression (although this time in the Phrygian mode moving by step from F\# minor to $\mathrm{G}$ major and returning to the F\# minor) and shares some of the syncopated accents of the highlife bassline. The vocal line in the chorus maintains an F\# throughout, over both the F\# minor and the $\mathrm{G}$ chords, emphasizing the tonic and becoming a melodically discordant major $7^{\text {th }}$ above the tonic G. In contrast, "Ide Bee" is in F sharp minor, with a standard Western pop minor chord progression (vi IV I V), "Obaanie" in C major is a variant (I V vi IV / I V IV - ) and "Brooni" has an ascending bassline with a tonic and upper neighbor suspension chord which finally outlines a $\mathrm{V}$ - I progression, reminiscent of a Christian Gospel tune. These latter three pieces lack the idiomatic highlife guitar, bassline and the semi-tone apart chord themes, although the close harmony, sometimes with "wrong" notes, gives some sense of the pieces being linked to the highlife tradition.

Click here for audio.

Appietus feat. KK Fosu \& Reggie Chorus, "Ma Alomo." The Revolution. Appietus, 2010 by Akwaaba Music.

(Adobe Reader may be required to listen to audio files. The software may require your permission to access this media.)

Figure 2. Appietus feat. KK Fosu \& Reggie Chorus, "Ma Alomo," Reduction, 0'30" The Revolution (2010)

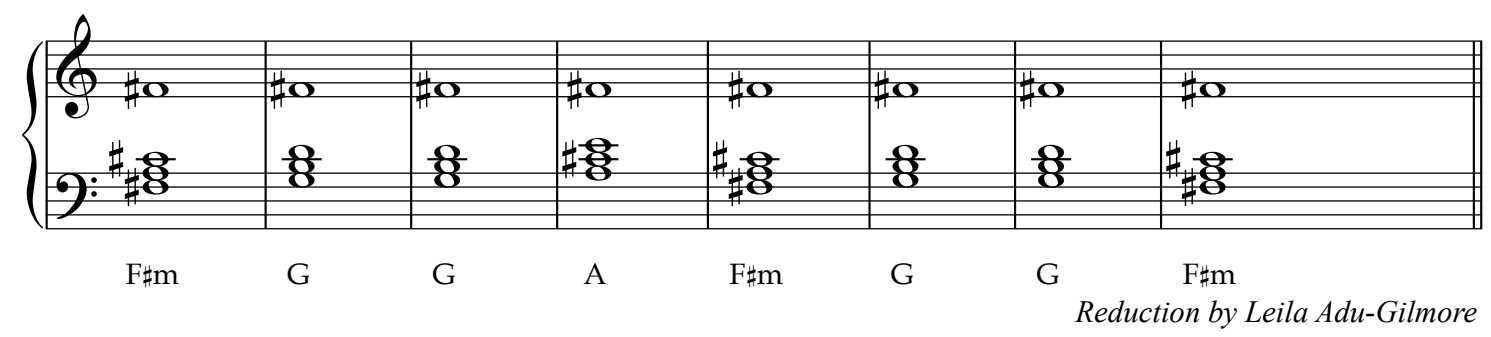

Also in "Emere," one of the more recognizable features of highlife, the typical highlife bassline (Figure 1.2) is clearly delineated. The syncopated feel of the highlife bassline is accentuated by the fifth of the tonic chord, as can be seen in the second measure of "Emere" (Figure 1.2) where $F$ is the root. The $C$ is played in two octaves, followed by a $G$ neighbor tone to the root note $F$. The third measure begins with the root of the chord $E$ and then leaps up a fifth to the $E$ and down the octave to the lower $E$, again accenting the fifth of the chord. The fourth measure outlines the $E$ chord, along with a neighbor tone $F$ and is followed by a fifth measure in which the second, third and fourth beats feature the fifth of the tonic. Hence, the highlife pattern of a 12/8 syncopated bassline, which is ornamented and varied with octave, leaps and neighbor is present.

Parallel vocal harmonies are a particular feature of highlife, dating back to earlier traditional folk songs, such as the female folk song style, nwonkoro. This counterpoint creates some "discordant" harmonies when coupled with diatonic triadic instrumental accompaniment. Another of the characteristic aspects of highlife is the outlined diminished fifth within a seemingly standard harmonization. In "Bronii" the third chord has a flat seven that outlines a diminished fifth between the outer voices. This is left unresolved and unanswered, however, with only the melodic line completing the phrase.

Features of highlife and hiplife vocal lines are descending, ornamented melodic lines and two- and three-part parallel vocal harmonies sung in Ghanaian languages, in this case, Twi. "Emere" features highlife singer, Sarkodie, singing a parallel fifth harmony with a robotic voice at the beginning of the track (0'18"). "Bronnii" has a lead vocal, with parallel harmonies (Figure 3.2) alongside a rising bass line, ending with a solo lead vocal line descending over the final chord in the progression. The vocal line of "Ma Alomoo" ascends in parallel passing chords and "Emere" descends in passing fifths.

\section{Click here for audio.}

Appietus feat. Kofi B, "Bronnii." The Revolution. Appietus, 2010 by Akwaaba Music.

(Adobe Reader may be required to listen to audio files. The software may require your permission to access this media.) 
Figure 3.1. Appietus feat. Kofi B, "Bronnii," Reduction, 0'22"

The Revolution (2010)

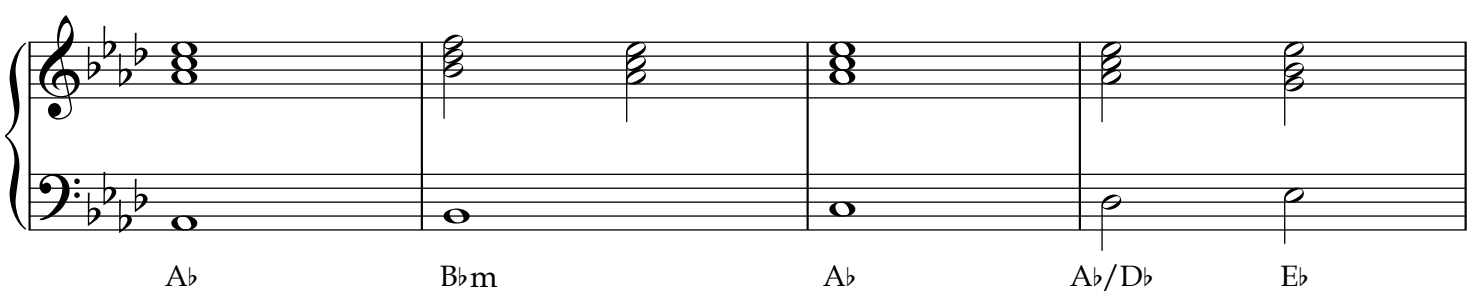

Figure 3.2. Vocal Harmony Reduction, 0 '29"

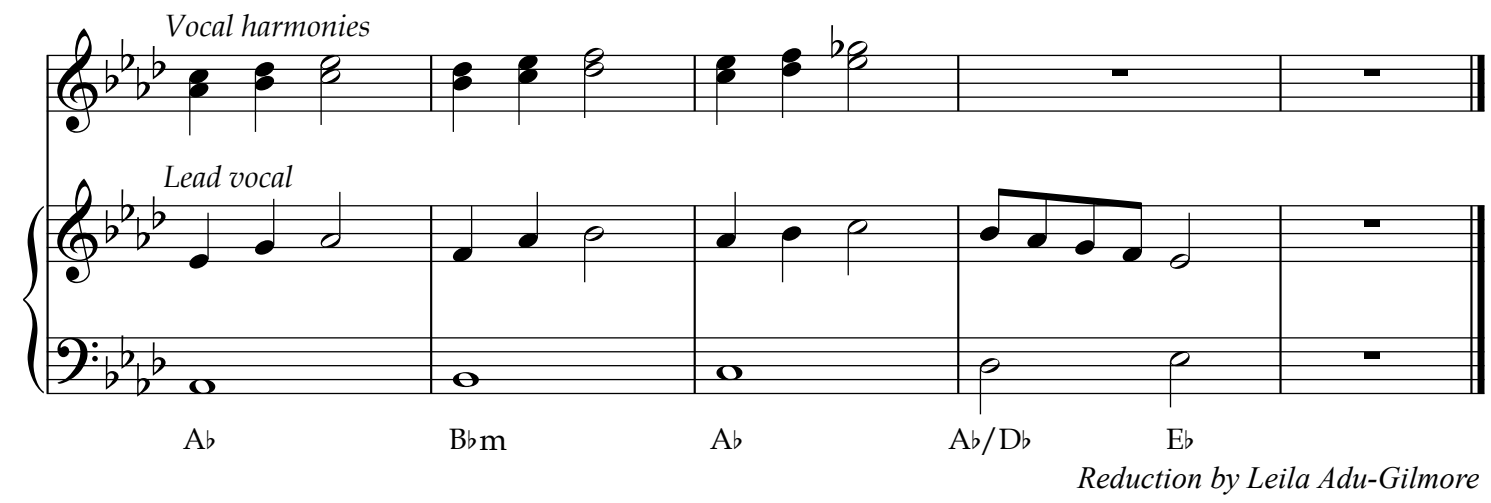

Hence, Appietus expertly uses his imaginative harmonic sensibility to paint a sonic palette of traditional highlife harmony and bass lines, Ghanaian traditional vocal parallelism and western popular music and beyond.

\section{"Tonga": An Ecological Analysis}

On the first downbeat, an almost imperceptible glissando reveals a smooth synthesized sine tone (F3) eighth note that repeats on the off-beat and is echoed by reverb and digital delay effects. DJ Breezy's distinctive motif for "Tonga," less than a second of empty space, separates the next iteration. Enter the voice of rapper Joey B who knowingly chuckles and is answered by an enthusiastic raga-style call from another voice (0'01"), the use of delay effects on both voices implies space. Typically, in EDM, new musical characteristics enter after four measures; here the crisp and unaffected high-hat playing 3-2 clave pattern (0'03"), creates a sharply pointillistic attack, contrasting with the space of the previous sound objects. The second offbeat is accented with a high synth sound, giving us an off balance feel. On the third set of four measures, a sinister synth (0'09") stab comes in and no new material is added until the groove finally settles. A low pitched synthesized tom-tom drum lands on the first beat ( $\left.0^{\prime} 17^{\prime \prime}\right)$ and a medium pitched drum on the third beat with a higher on the second and fourth, producing a sloping feel from duple and quadruple accents. At the same time Joey B's rap comes in with the verse. His voice has a slight reverb and he raps in a relatively quiet and relaxed manner, close to the microphone, The microphone technique, coupled with his laughs, suggests an intimacy and light-heartedness juxtaposed with the harsh sonic background. The chorus (0'53") uses the initial repeated eighth note figure on the same F3 pitch to repeat the word "Tonga." This is layered with unison voices and sinister synth stabs repeated on a doubled $G$ and then $G$ to $F$ in each measure. He satisfies this expectation of this four bar event rhythm but does so with the least amount of material possible, maintaining the minimalist theme. There are no chords and keyboard harmonies played by a keyboard or other instruments, there are no vocal harmonies and there is no busy bassline. The inclusion of silence in the music and the large differences between the pitches of the sounds, create a sense of space, while emphasizing the clave pattern by leaving the high hat in high-pitched frequency zone by itself. The minimal use of resources in "Tonga" leaves space for the audience as listeners while 3-2 clave and accents give groove to the audience, as dancers.

Click here for audio.

Joey B (feat. Sarkodie), "Tonga." DJ Breezy, 2014 by Black Avenue Music. Produced by DJ Breezy. (Adobe Reader may be required to listen to audio files. The software may require your permission to access this media.)

\section{Between Composition and Improvisation: Findings on "Process"}

In order to analyze this music, it is necessary to take the blurring of composition and improvisation in the studio into consideration. I am using the term "process" to refer to the way that composition and improvisation are 
always impacting each other in the studio environment. By interrogating the relationship between improvisation and composition in the music of these two producers, I discovered the similarities of process that could be found and interpolated into two types. As a composer may habitually use a compositional technique like retrograde inversion, or a jazz pianist may use a scale over a particular chord, producers repeatedly deploy their own processes. Both producers use the computer software Fruity Loops to create the rhythm track and Cubase for the final production. Appietus says: "I went through the hustle. So what I do is different, the texture is different, my thinking is different and I have become addicted to the ways I do things." I discovered through interviews, with Appietus (August 19, 2014) and DJ Breezy (August 21, 2014) that both use two different processes to begin a new piece, 1) starting a piece from scratch and adding to it, or 2) starting a piece using existing source material as inspiration, such as music samples or sound from film and adding to it.

\section{Type 1-process from scratch}

Appietus vocalizes a rhythm from his own inspiration:

I have a certain language I do myself if you listen . . . now everybody loves it, they want to do that, I don't know what I'm saying but I just mumble words, and I make noise "dededeededee" to excite myself, put myself in the mood, maintain it and then I create the beat because sometimes I'm here alone, there's no artist.

Each sound of this vocalization corresponds to what will become separate instruments in the track. Later, when I asked how he writes the chords, he demonstrated with another vocalization, singing two different Latin piano parts.

Adu-Gilmore: Do you improvise at all when you are creating tracks?

Appietus: Yeah, every time I improvise.

A-G: How would that be like, on the keyboard or ...?

A: Drums, everything. 'Cause usually I get an idea in my head, and you see the timing of the drum, so I'm getting [vocalizes $6 / 8$ drum pattern]. So I start separating them [ding dong ding ....] those are toms, [ ... ] is a kick, here is a snare, this is percussion so I keep separating them and I start using the Fruity Loops to generate it. And I keep on with the melody in my head, I create melodies as I go and then I follow that melody with the piano. And like this you have the beat, I always do it . . so improvisation is the thing.

In the next stage, he adds synthesized and sampled instruments using a keyboard. Appietus unpacks his method of keyboard improvisation:

Even [with] my finger on the piano, when I'm playing, professionals get confused because they think I'm going to make a mistake. You know? They think you have to do this but I think if I keep to the rule, you know, I will not be free. And to me, what is school? We all go to school to learn on other people's experiences, what other people's research has brought them, so what about your own research? I am a product of my own research and hard work and the grace of God.

DJ Breezy also uses the method of beginning a track from scratch, He explains that sometimes, when he begins a track, an untraceable sound will ring in his ears and he will try to make a melody out of it. When he created the motif for "Tonga," he remembers saying to Joey B:

"I have this chorus rhythm in mind and I think you have to put something to it." He [Joey B] was like, "oh okay then, just start something, let's see how it goes." So the chorus is going "Tonga, (clicks fingers) Tonga (click) Tonga," so I have to sit down and see what I add to that and make a hit ... you have the foundations and then you have to develop (author's note: plays rhythm and Joey B adds words).

Like Appietus, for the beat Breezy starts with the drums but instead of vocalizing the rhythms, he arranges them straight into Fruity Loops. He also has a drumpad that he can use if he is feeling energetic and in the mood to play the beats himself.

In terms of the overall shape of the arrangement, Appietus says that he does not stick to a standard verse/chorus pattern. He predetermines the piece by making a beat and creating an arrangement of verse/chorus pattern the way that he wants before the artist hears it. DJ Breezy states his preference for beginning a track from scratch before receiving words from the artist. He, however, alters the arrangement to fit the words from the artist. 
Type 2-process on source material

Appietus uses inspiration from music and other media sources.

Sometimes I heard something, or subconsciously, you know you heard something and it keeps ringing in your head but you don't know what it is. So, then I decide to do something that will excite my friends.

I can even listen to something, maybe I'm watching TV, it's a movie soundtrack, and it's different, you know those things, you never hear them anywhere except you watch that movie? So it's unique, so I like doing that, I listen to the kind of music, or sometimes, it's because some people are fighting at some point and it's aggressive and it's happening but you can get some ideas from it. So I improvise a lotfrom different sources.

DJ Breezy is also inspired by outside sound sources when he is not in "the zone" or the right mood to make a beat. He uses samples from another producer's recording, changing something that may have been a minor component into a major part of his new composition. However, when I asked if he ever starts things from scratch, he said that he always starts things from scratch, even though he is sampling. In fact, he only thinks that it is copying if you take the whole composition, chords and melody. ${ }^{5}$ Breezy admitted that bass lines are not his strongpoint and so he leaves the bassline till he has finished the other layers and sees what the track needs. For harmonic content, he waits until the artist starts singing and then adds the harmonies while they are singing. In order to extend the musical idea, he adds different elements, like beats. He emphasized using (sampled and synthesized) musical instruments that are suitable to that genre. Structurally, both artists are able to build on words, or songs, from the artist but prefer to begin the process from scratch.

Structurally, both artists can work with other artists, building on their work in different ways. Appietus states that he can also make a beat for a particular song. DJ Breezy works in collaboration but in an improvisatory manner, editing with the vocal artist's needs in mind in order to define the structure. He says that the primary function of the words is to provide a rhythm: "when you have a rhythm, you can make the music. It's not about the words." When the beat, or composition, is finished, it is given to the vocal artist and he then records the artist singing their vocals. There is a dialogue between him and the artist, about the song structure, (i.e. the number of repeats of verse and chorus), then he edits and makes more adjustments.

Finally, knowing when to stop is just as important in composition as it is in improvisation. In composition, there is a continuum of writing, where the composer could keep adding material-because they are creating out of the temporal space, or time, in which the piece is being played. In freely improvised music, musical groups often stop and pause together, ending a piece, as if by magic. Electronic music producers also have to consider when a piece of music is complete. Appietus locates the end as follows: "Because then you are feeling it already. You can keep pushing it but you realize you will destroy it."

It emerges, then, that beginning a track, determining the larger elements of structure, and extending ideas and bringing them to completion are all subject to both improvisation and composition in these producers' music. Appietus insists that both types of creation are improvisation: "Because I imagine stuff, I get melodies in my head and then my tools help me do it ... That's why my name is 'Appiah and his tools,' so 'Appietus." Breezy says: "Like the harmonies and everything will come. Like this, if you add to that, it will sound like this." Both DJ Breezy and Appietus take an organic approach to process that embodies both composition and improvisation, beginning in two different methods of process and ending with different emphases on collaboration within musical structure.

\section{Local Formal and Informal Networks of Education and the Internet}

Local informal and formal networks of education play a central role in understanding the growth of outside musical influences on DJ Breezy and Appietus. Appietus was educated first in the church, then, twenty years ago, he took courses and learned on-site at Fredyma Studios, Kay's Frequency Studios, and finally in Kamsite Studios. Appietus has taught younger and newer artists how to play the keyboard, which he learnt in church:

I was very young, like eleven and I would go and disturb them. When the guy is playing the drum, I would be hitting with a different stick ... When the guy is playing, I be pressing the note. Bing bing bing bing bing. So l'm messing the whole music in the church, so they said: "let's teach him to know how to play and give him some small piano." So they taught me and gave me a small piano, I used my headphones, so when they are playing I am also playing with them, but I can hear only me, can hear what I'm playing. So I don't disturb the whole church. So that's how it started and then the guy had to go to university and I became the official. So by age thirteen, I was a professional . . .

I'm still learning the piano, believe me. Every day l'm gaining new ideas. When you love it, it's addictive. 
Appietus worked with highlife musicians like Daddy Lumba, and he says that highlife is the oldest music in the country. When I query this and ask him about traditional drumming, he says that sometimes producers fuse it into a track, but that nobody focuses on it (except at cultural centers, for ceremonies ${ }^{6}$ or for Independence Day.)

When I asked how he composes his music, he brought up the subject of the morphing genre of highlife and the dissolution of the old:

The trends are always changing and so we are adapting. We are adapting and l'm a pianist, so it's easy to adapt . . . Cause the highlife I started playing way back, it's changed so much. It's not the same authentic highlife, it keeps moving, it's [be]coming modern, new ideas are coming, so when you stick to the old one, nobody wants to work with you. Because everybody wants what is trendy.

With no formal or informal education in highlife, DJ Breezy is further removed from traditional Ghanaian music. I find it surprising that for me as an outsider highlife seems to have unique bass lines, vocal parallelism, and an idiomatic rhythmic and harmonic interplay between instruments, for Breezy the timbre of guitar is all that is needed to define highlife as a genre. When asked about it, he placed emphasis on the instruments used for the genre.

Adu-Gilmore: Does traditional Ghanaian music feature in your music? Like highlife?

Breezy: You know like highlife is because of the instruments that you use . . .

A-G: And what's the highlife bit that you put in? Is it the notes, the singing?

B: No, yeah, I think it's the kind of instruments that you use . . . the live guitar . . that makes highlife.

Breezy said that percussion is used a lot in African music and that this has entered into African hip hop. He noted that contemporary afrobeats artists will use proverbs and old themes and "just play around it" with rap or singing. So far as content is concerned, the vocal artist is responsible for the lyrics. He gave the example of "Tonga," as a theme. He says that music is not "high" (as in "high art") like it used to be, "so far, afrobeat is just about dancing . . You know, put a smile on people's faces, that's it." Therefore, traditional highlife and gospel harmony and piano skills informed Appietus' formal and informal local education, whereas DJ Breezy's local training is limited to the surface element of instrumentation.

Although both producers learn through the Internet, DJ Breezy's education was exclusively informal and almost entirely Internet based. When DJ Breezy realized that he wanted to be a producer, there was no one to teach him. He says that he came from a "typical village ... with no light, no electricity, no water" and then went to high school in the city, where he began teaching himself by using some of his school money to go to Internet cafes and learned software through YouTube tutorials. Breezy listens for chords from other producers to develop his compositions. He believes that music is universal, that it is possible for two people to think of the same chords and harmony at once, as long as you don't take the whole composition. Breezy says that the keyboard used to be the most important factor in hip hop and that now producers use the keyboard less and let the beat and the arrangement carry the song. He plays keyboard in the studio to compose but does not consider himself a keyboard player, relating that he can play a couple of Gospel tunes but could not play out in concert. The American producers that he cites as influences, Timbaland and Pharrell, are experts of timbre and are noted by Questlove as pioneers in the minimalist hip hop scene (Thompson and Greenman 2013, p. 180); DJ Breezy also refers to Trey Songz,' "Oh Nana" produced by DJ Mustard and hearing his own "Tonga," in a club as songs with minimal use of keyboard that are very distinctive: "and that from the moment, you are even at the back, like far away, you hear that song, you will be like, "yeah, they are playing 'Tonga.'" Other African electronic musics, like Nigerian afrobeats and kwaito, South African house music, have taken a similar minimalist route. As well as American producers, DJ Breezy admires Ghanaian producer Q-Beat (official producer for R2Beats). Breezy still learns from the Internet and is still self-teaching, saying that it is important to create new music by continually exploring new techniques. Every day he contacts producers:

to see if they have new things that I don't know about... Even when I'm working on a song and maybe I'm having a difficulty, like maybe how to mix or how to master a song, it happens to every producer, so ah like when I'm having a difficulty I call and ask like "Yo, how do you this, how do you do this?"

Breezy will ask other producers to complete tasks if he cannot get the results that he wants. "In this business you don't have to feel too big to ask, you have to know, you have to learn." Although for Appietus, formative musical education began at church and the studio, he also continues to expand his informal education in production skills through the Internet:

Everything is changing, this equipment or the new stuff is going to change by next year, so I am reading online. You know, companies when they are going to bring a product, they are going to talk about it 
extensively, you know that: "oh we are going to do, we are going to do, we are going to change the next generation of sound." You know the marketing so. And they are telling the truth, so you go online and you read about it, so you know what to buy, so you get the best sound. I record in ninety-six thousand kilohertz ... Yeah, because I want to maintain some standard, so I don't mess with my sound.

The trends are always changing and so we are adapting. We are adapting and I'm a pianist, so it's easy to adapt.

In sum, Appietus' piano skill and harmonic sensibility along with his dedication to new international trends and technology have kept him relevant in the world of hip hop, hiplife and afrobeat and pop, whereas Breezy is more musically influenced by hip hop through informal training. "Tonga" shows the crest of a sea-change in African music minimalism due to its sonic similarities to and influence of African-American minimalist hip hop.

\section{Music Production in the Environment of Accra: Opportunities and Obstacles}

In 2014, I revisited Ghana after a fifteen-year absence and although there is a more stable voting system, it has found oil, and many Ghanaian expats have returned to invest in Ghana's future, obstacles affect all areas of daily life and work, including the process of music production for Appietus and DJ Breezy. When I visited Appietus, he was dealing with someone whose laptop had been stolen at his studio and detaining the suspected thief's friend, as the police are slow to react. Since visiting Ghana, all of DJ Breezy's computer gear and his entire musical output have been stolen. ${ }^{7}$ Power outages can last many hours, even whole days. ${ }^{8}$ For producers working in the electronic medium of the music studio and computer, the implications are obvious. Appietus illustrated the bad current by pointing out the flickering lights. To deal with this and with "lights out," he has a generator outside that is bigger than his car. Although changes are promised, Appietus says that he will be the first to join in using solar power, which is already being tested by foreign investors in Ghana. My interviews with Breezy were delayed by days due to power outages at his home, so we waited till a day that we could go to the studio where he works, where there is a generator. Appietus said that there are also delays due to the faulty water systems causing floods, as well the terrible traffic jams that can afflict Accra, making a half hour journey last half a day.

Waters get flooded and the artist will say, "I can't come because my area is flooded by the storm," or "my car is flooded, so I have to stay home." Or "my car is soaked in water." Or "it's drowning" or something. You get used to it. Or "I can't make it because there's too much traffic."

Breezy said that, were he in the UK or the US with a functioning royalty system, the success of songs that he has already produced would mean that he could retire and live off the money. However, he explained that the system of music royalties (De Beukelaer 2012) does not function in Ghana, a fact that undermines the work of producers and music writers. Breezy works in another producer's studio and explains that having his own studio would be difficult. Ghanaians cannot buy products outside of Ghana with the local currency, cedis (which are low against the dollar) and products in dollars are expensive.

Now it's bad like, the system just fallen totally like, it's bad it's bad. Like now I think one dollar is like four five cedis now and it's bad. Just imagine, maybe you are buying, maybe a speaker, a monitor, like maybe one pair, like two hundred or three hundred dollars, just like three hundred times four. So, you spend a lot, you spend a lot.

Additionally, visas for Ghanaians for travel outside of Ghana are slow to obtain, making it difficult and sometimes impossible to promote or tour internationally. Hence, the environmental and financial challenges affecting Ghanaians involved specificities that impact music production for Appietus and DJ Breezy.

The studio environment of the two producers is similar. Appietus has been working in his own studio, Creative Studios, for eight years. He chose the area because it is his father's property and he changed the sound in the studio by insulating everything, including the ceiling and doors with cushions. Both producers can also use a laptop when they are at home, making musical sketches with the possibility of developing the piece in the studio. Breezy also works in a mobile studio, for example, when he is needed for artists to DJ on the tour at awards shows. The mobile studio gives them a chance to set up in a hotel room and create new music.

On a positive note, Breezy said that a benefit of being in Ghana is that there is not a saturation of producers in the country as there would be in America. He says that by trying really hard in Ghana, he has risen to the top and that he even has more chances to be heard than if he were in the US. When I asked specifically about producing music in Ghana, the producers responded with comments about the day-to-day aspects. Breezy's comment was that the weather is hot and this is expensive for air conditioning. For Appietus, who was in a position to compare the situation in Ghana to that in London, the conditions and pace of life in Ghana are becoming conducive to producing music: 
A-G: So you said you've got a studio in Camden too. What's the difference between recording there and here? How does it affect you being in Ghana recording?

A: Most of the time, you know most of the people live up there [London] and for some reasons they cannot come down [from London] to do their own stuff, maybe because of work and all that, so maybe they only have a few days off. So when I go there it's very helpful I mean just, we're able to record, a lot of people have a passion for music but you know how it is to live outside, they do all sorts of jobs to survive but what they really want to do is music, so when I go there, they get an opportunity to record.

Therefore, although both producers found that there are difficult logistical aspects of producing in Ghana, Appietus' overall experience is that Ghana is conducive to creating music when compared with producing overseas.

\section{Conclusion}

Interviews with Appietus and DJ Breezy show that their process is embedded firmly in both pre-composed and improvised methods of music-making. The blending of interview material and analysis (through transcription, reduction, and ecological acoustics) examines distinct threads of Ghanaian and international music styles, their paths through different formal and informal networks of education and the environmental effects on their process. Thus, although these producers refer to the singer or rapper as the "artist," they show us that in the field of EDM in Ghana and abroad, the producer well deserves the term and demands re-categorization of the title "producer" to include both composer and improviser.

An analysis of these producers' processes requires looking at both musical elements as well as the resources of education and environment, changing the way that we read these contexts by foregrounding the music itself. In the case of Appietus' music, transcriptions show Ghana's unique thread of Highlife harmony and its idiomatic harmonic tendencies, whilst interview material on process shows his unique methods of vocalization in combination with production tools that are informed by local formal and informal educational networks and the Internet. The environment of Accra (in comparison with his London studio) shows the way that Appietus is enabled with time and space to work with artists. On the other hand, DJ Breezy's interview material shows that his minimalist hip hop tendencies are due to his influences, his lack of keyboard training through his informal training through other producers and the Internet, and positively reflects his assertion that this lack of keyboard is a global trend in hip hop. In addition to this interview material, initial listening to "Tonga" shows this minimalist tendency and critical analysis through ecological acoustics gives a clearer timbral picture, revealing his skill in contrast, silence and spatial effects, without disadvantaging the analysis through its minimal harmonic activity. In the context of environment, although there are strong positive aspects of producing in Accra for both producers, such as Appietus having time to produce and DJ Breezy being part of a small local pool of producers in the capital city, for Breezy, these have been outweighed by the setback of theft of his musical gear and output. Using critical analysis in the study of contemporary Black music of the Global South, through techniques such as transcription, reduction or ecological acoustics, and considering the context of the music in a different environment, with different networks of education, encourages a deeper understanding of process through mutable and changing methods.

\section{Notes}

${ }^{1}$ The Latin ' $3-2$ ' clave rhythm is a variant that has three beats close together, with a pause and then two beats close together (where " $x$ " is a hit and "." is a pause) and sounds as follows: $x \ldots x \ldots x \ldots x . x \ldots$

${ }^{2}$ Auto-tune was originally used to digitally force a singer's voice to be in tune and was popularized as artistic effect in the chorus of Cher's "Do You Believe in Love." It has since been used by other artists, dubbed the TPain effect.

${ }^{3}$ Aaron Allen regards the spatial aspects of sonic analysis and provides a disambiguation of the term "ecological acoustics," ("Environment is the nonhuman physical world . . Ecology, on the other hand, is holistic, relating to the 'eco-' prefix (from the Greek root oikos, 'household'), and constituting the web of relationships of all living organisms, including humans, with their contextual physical environments. Related to both environment and ecology, architects and urban planners use built environment to refer to humans' manufactured world of dwellings and buildings, infrastructure, constructed landscapes, and urban social spaces, as well as the interactions of these places with each other and humans" (392). Eco-criticism is a field of literature studying cultural products (text, film, advertising, other media, etc.) that imagine and portray human-environment relationships variously from scholarly, political, and/or activist viewpoints. Thus, ecomusicology is not "ecological musicology." In his article "How Do We Hear In The World? Explorations in Ecological Acoustics," William Gaver explains that "in seeking to expand accounts of sound and hearing beyond the traditional preoccupation with sensations such as pitch and loudness, we must develop a framework for describing ecologically relevant perceptual entities: the dimensions and features of events that we can actually hear" (287, italics mine). For 
further reading on ecological acoustics, see also Eric F Clark's, Ways of Listening: An Ecological Approach to the Perception of Musical Meaning.

${ }^{4}$ The guitar is cited by both Appietus and DJ Breezy as the main instrumental component of highlfe. Interestingly, brass band instrumentation, made popular by highlife bands such as ET Mensah, is not mentioned by these producers, nor is it a regular feature of the hiplife genre in the same way that guitar is.

${ }^{5}$ Traditional African music does not traditionally involve the concept of ownership of composition. This is similar to hip hop sampling, where a recording of other music is part of the composition. As Breezy is Ghanaian and also producing in the hip hop idiom, this question of agency is not given importance, or even noticed, in his role of producer/composer.

${ }^{6}$ Here, Appietus is talking about production, specifically in Accra; however, it should be noted that traditional drumming is still an important part of ceremonies, such as funerals.

${ }^{7}$ DJ Breezy's musical equipment, musical content and personal belongings were stolen in April 2015. http://www.ghanaweb.com/GhanaHomePage/entertainment/Robbers-ransack-DJ-Breezy-s-studio-make-awaywith-everything-354099

${ }^{8}$ The rapper Wanlove from the FOKIN BOYZ wears an ECG helmet around Accra and in music videos in a mockery of the bad electricity service.

\section{Works Cited}

Agawu, Kofi. Representing African Music: Postcolonial Notes, Queries, Positions. New York: Routledge, 2003. Print.

Allen, Aaron S. "Ecomusicology: Ecocriticism and Musicology." Journal of the American Musicological Society 64.2 (2011): 391-94. Print.

Appiah, Kwame Anthony. The Ethics of Identity. Princeton: Princeton U P, 2005. Print.

Appietus. Personal Interview. 19 Aug. 2015

---. The Revolution. Prod. Appietus. Akwaaba Music, 2010. MP3.

---. Tip of the Iceberg. Prod. Appietus. Akwaaba Music, 2013. MP3.

Attias, Bernardo Alexander, Anna Gavanas, and Hillegonda C. Rietveld, eds. DJ Culture in the Mix: Power, Technology, and Social Change in Electronic Music. New York: Bloomsbury, 2013. Print.

Body, Jack. "From Sound to Symbol and Back Again: Transcription/Composition." www.jackbody.com. N.p., 1990. Web. http://www.jackbody.com/pages/sound_to_symbol.htm

Butler, Mark. Playing with Something That Runs: Technology, and Composition in DJ and Laptop Performance. Oxford; New York: Oxford UP, 2014. Print.

Carl, Florian. "From Burger Highlife to Gospel Highlife: Music, Migration, and the Ghanaian Diaspora." The Globalization of Musics in Transit. Eds. Simone Krüger and Ruxandra Trandafoiu. London: Routledge, 2013. 251-272. Print.

Clark, Eric F. Ways of Listening: An Ecological Approach to the Perception of Musical Meaning. Oxford; New York: Oxford UP, 2005. Print.

Collins, John. African Musical Symbolism in Contemporary Perspective: Roots, Rhythms and Relativity. Berlin: Pro Business, 2004. Print.

---. "Contemporary Ghanaian Popular Music." Hip Hop Africa: New African Music in a Globalizing World. Ed. Eric Charry. Bloomington: Indiana UP, 2012. 211-231. Print.

---. “Ghanaian Highlife.” African Arts 10.1 (1976): 62-68. JSTOR. Web. 31 Aug. 2015. 
---. Personal Interview. 22 Aug. 2015

De Beukelaer, Christiaan. Developing Cultural Industries: Learning from the Palimpsest of Practice. Ed. Odile Chenal and Bas Snelders. European Cultural Foundation, 2012. Print.

DJ Breezy. Personal Interview. 21 Aug. 2015

Eno, Brian. "The Studio as Compositional Tool." Audio Culture: Readings in Monder Music. Eds. Christopher Cox and Daniel Warner. London: Continuum, 2012. 127-30. Print.

Gavanas, Anna, and Rosa Reitsamer. "DJ Technologies, Social Networks and Gendered Trajectories in European Cultures." DJ Culture in the Mix: Power, Technology, and Social Change in Electronic Music. Eds. Bernardo Alexander Attias, Anna Gavanas, and Hillegonda C. Rietveld. New York: Bloomsbury, 2013. 54-60. Print.

Gaver, William W. "How Do We Hear In The World? Explorations In Ecological Acoustics." Ecological Psychology 5.4 (1993): 285-313. Print. https://www.gold.ac.uk/media/migrated/media/goldsmiths/departments/researchcentres/interactionresea rchstudio/pdf/10gaver.whatDoWeHear.ecopsych93.pdf

Hancox, Dan. “The Rise of Afrobeat,” The Guardian. Guardian News and Media Ltd., 9 Jan. 2012. Web.

Jaji, Tsitsi Ella. Africa In Stereo: Modernism, Music, And Pan-African Solidarity. Oxford: Oxford UP, 2014. Print.

Joey B. (feat. Sarkodie). "Tonga.” Prod. DJ Breezy. Black Avenue Music, 2014. MP3.

Kaye, Andrew L. “Koo Nimo: A Contemporary Ghanaian Musician.” African Music 7.4 (1999): 147-65. Print.

Le Brave, Benjamin. Personal Interview. Aug. 2015

Lewis, George E. A Power Stronger Than Itself: The AACM and American Experimental Music. Chicago: U of Chicago P, 2008. Print.

Lipsitz, George. Dangerous Crossroads: Popular Music, Postmodernism and the Poetics of Place. London: Verso, 1994. Print.

Perry, Imani. Prophets of the Hood: Politics and Poetics in Hip Hop. Durham: Duke UP, 2004. Print.

Pras, Amandine, Caroline Cance, and Catherine Guastavino. "Record Producers' Best Practices For Artistic Direction-From Light Coaching To Deeper Collaboration With Musicians." Journal of New Music Research 42.4 (2013): 381-95. Print.

Radano, Ronald. Lying up a Nation: Race and Black Music. Chicago: U of Chicago P, 2003. Print.

Schloss, Joseph G. Making Beats: The Art of Sample-Based Hip Hop. Middletown: Wesleyan U P, 2004. Print.

Shipley, Jessie Weaver. Living The Hiplife: Celebrity and Entrepreneurship in Ghanaian Popular Music. Durham: Duke UP, 2013. Print.

---. "The Birth of Ghanaian Hiplife: Urban Style, Black Thought, Proverbial Speech." Hip Hop Africa: New African Music in a Globalizing World. Ed. Eric Charry. Bloomington: Indiana UP, 2012. 29-36. Print.

Smith, Val. Not Just Race, Not Just Gender: Black Feminist Readings. New York: Routledge, 1998. Print.

Thompson, Ahmir-Khalib, and Ben Greenman. Mo' Meta Blues. New York: Grand Central, 2013. Print.

Weheliye, Alexander. Phonographies: Grooves in Sonic Afro-Modernity. Durham: Duke UP, 2001. Print.

Wergin, Carsten, and Fabian Holt, eds. Musical Performance and the Changing City: Postcolonial Contexts in Europe and the United States. New York: Routledge, 2013. Print.

Young, Kevin. The Grey Album: On the Blackness of Blackness. Minneapolis: Graywolf, 2012. Print. 